\title{
COMMENTARY
}

\section{Metformin-induced lactic acidosis: no one left behind}

\author{
Sarah Vecchio ${ }^{1}$ and Alessandro Protti2* \\ See related research by Friesecke et al., http://ccforum.com/content/14/6/R226
}

\begin{abstract}
Metformin is a safe drug when correctly used in properly selected patients. In real life, however, associated lactic acidosis has been repeatedly, although rarely, reported. The term metformin-induced lactic acidosis refers to cases that cannot be explained by any major risk factor other than drug accumulation, usually due to renal failure. Treatment consists of vital function support and drug removal, mainly achieved by renal replacement therapy. Despite dramatic clinical presentation, the prognosis of metformin-induced lactic acidosis is usually surprisingly good.
\end{abstract}

In the previous issue of Critical Care, Friesecke and colleagues demonstrate that the survival rate of patients with severe lactic acidosis due to metformin accumulation can be strikingly higher than expected based on the initial clinical evaluation [1].

Metformin is nowadays the first-line drug of choice for the treatment of adults with type 2 diabetes [2]. This drug is the sixth most frequently prescribed in the USA $(>50$ million prescriptions in 2009) and is taken by almost 1.5\% of the Italian population $[3,4]$.

Metformin is a safe drug when correctly used in properly selected patients. In particular, no cases of lactic acidosis (a relatively common side effect of other biguanide compounds) were reported in 347 trials with 70,490 patient-years of metformin use [5]. Real life can differ from research settings, however, and lactic acidosis has been repeatedly, although rarely, observed in patients treated with metformin. The number of inquiries to the Swedish Poison Information Centre for metformin intoxication has increased 10 times during the past

\footnotetext{
*Correspondence: alessandro.protti@policlinico.mi.it

2Dipartimento di Anestesiologia, Terapia Intensiva e Scienze Dermatologiche,

Università degli Studi di Milano, Via F.sco Sforza 35, 20122 Milano, Italy

Full list of author information is available at the end of the article
}

decade, with 25 cases of severe lactic acidosis reported in 2007 and 2008 [6]. According to the American Association of Poison Control Centers, metformin may have contributed to 21 fatalities in the USA in 2008 [7]. Fortynine cases of lactic acidosis and accidental metformin accumulation were reported to the Poison Control Centre of Pavia (Italy) from January 2005 to August 2010, resulting in 11 deaths. Since metformin use is constantly increasing - there has been a 10 to $15 \%$ rise in prescriptions per year in the USA and Italy [3,4] - related cases of lactic acidosis may become less rare.

The term metformin-associated lactic acidosis refers to any case of lactic acidosis that develops in a patient treated with metformin, with no further mechanistic insight. In most of the cases, however, lactic acidosis cannot be directly attributed to metformin use but rather depends on concomitant low cardiac output, anemia, hypoxemia or liver failure. The term metformin-induced lactic acidosis specifically refers to cases that cannot be explained by any major risk factor other than metformin overdose [8]. The distinction between these two entities is sometimes very subtle and metformin accumulation may coexist with other risk factors, all contributing to the pathogenesis of lactic acidosis.

The present case series includes 10 patients admitted to intensive care with lactic acidosis and metformin accumulation due to renal failure [1]. At admission, arterial $\mathrm{pH}$ was $6.75 \pm 0.13$ and lactatemia was $19 \pm 5 \mathrm{mmol} / \mathrm{l}$. The Simplified Acute Physiology Score II was $88 \pm 23$ and the predicted mortality was $96 \%$. Eight (80\%) patients had a cardiac arrest during their stay in intensive care. Treatment consisted of vital function support and renal replacement therapy. Despite the dramatic severity of clinical presentation, hospital survival was 50\%. Conversely, there were no survivors out of 31 patients with similarly severe lactic acidosis from other causes (mainly cardiogenic, septic or hemorrhagic shock) who were admitted to the same institution during the same period of time.

This finding is in line with previous observations. In 49 patients treated with metformin who developed severe lactic acidosis, survival was $17 \%$ among those with no 
drug accumulation (that is, lactic acidosis was actually due to another precipitating event) and was $71 \%$ in those with metformin accumulation, despite a similar severity of hyperlactatemia [8]. In another series, one out of 10 (10\%) patients with lactic acidosis probably due to metformin accumulation actually died despite an initially predicted mortality of around 55\% [9]. We have recently reviewed the data for 24 critically ill patients with lactic acidosis and proven or probable metformin intoxication. Despite an expected mortality of $70 \%$, observed mortality was $21 \%$. Even patients with initial arterial $\mathrm{pH}$ down to 6.62, lactatemia up to $33 \mathrm{mmol} / \mathrm{l}$ or Simplified Acute Physiology Score II as high as 87 managed to survive to hospital discharge [10].

That lactic acidosis carries a poor prognosis has been known for decades [11]. Lactic acid per se, however, is unlikely to be the explanation for this association. Lactate production is indeed an adaptive response to impending energy failure. This response provides some energy and a chance for cells to survive, even when oxygen availability or utilization are defective [12]. Cancer cells in a way provide the best evidence for lactate overproduction being an efficient response to hypoxia. By mainly relying on anaerobic metabolism, malignant cells can not only survive but even proliferate in a hypoxic environment, so that tumor growth can exceed angiogenesis [13]. According to the theory of lactate shuttles proposed by Brooks, lactate may act as an oxidative substrate exchanged between cells and tissues [14]. Acidosis itself may arise as an adaptive response to inadequate energy provision and may extend cellular viability [15].

The prognosis of lactic acidosis primarily depends on the underlying mechanism and on its reversibility. When lactic acidosis is due to metformin accumulation, then renal replacement therapy can efficiently remove the toxic substance (that is, metformin and not lactate!) and prognosis can be surprisingly good. The situation can be much more complex and less easily reversible when lactic acidosis is primarily due to severe hypoxia or tissue hypoperfusion.

Based on present and past observations, one may conclude that the decision to treat (or not to treat) a patient with suspected metformin-induced lactic acidosis cannot be based only on the severity of clinical presentation. We personally believe that treatment of the critically ill patient should always include drug removal, as long as metformin accumulation is thought to be responsible for severe lactic acidosis. Since a plasma metformin dosage is rarely available in most centers, intoxication should be considered highly probable whenever lactic acidosis and renal failure are uncommonly severe, other primary explanations are not evident and chronic metformin use is reported.

\section{Competing interests}

The authors declare that they have no competing interests.

\section{Author details}

'Centro Nazionale di Informazione Tossicologica - Centro Antiveleni, IRCCS Fondazione Salvatore Maugeri, Via S. Maugeri 10, 27100 Pavia, Italy. 2Dipartimento di Anestesiologia, Terapia Intensiva e Scienze Dermatologiche, Università degli Studi di Milano, Via F.sco Sforza 35, 20122 Milano, Italy.

Published: 21 January 2011

References

1. Friesecke S, Abel P, Roser M, Felix SB, Runge S: Outcome of severe lactic acidosis associated with metformin accumulation. Crit Care 2010, 14:R226.

2. Nathan DM, Buse JB, Davidson MB, Ferrannini E, Holman RR, Sherwin R, Zinman B; American Diabetes Association; European Association for Study of Diabetes: Medical management of hyperglycemia in type 2 diabetes: a consensus algorithm for the initiation and adjustment of therapy: a consensus statement of the American Diabetes Association and the European Association for the Study of Diabetes. Diabetes Care 2009, 32:193-203.

3. Top 15 US Pharmaceutical Products by Dispensed Prescriptions [http://www.imshealth.com/portal/site/imshealth].

4. Gruppo di lavoro OsMed: L'uso dei farmaci in Italia. Rapporto nazionale gennaio-settembre 2010. Rome; 2010.

5. Salpeter SR, Greyber E, Pasternak GA, Salpeter EE: Risk of fatal and nonfatal lactic acidosis with metformin use in type 2 diabetes mellitus. Cochrane Database Syst Rev 2010, 4:CD002967.

6. Personne M: Alarming increase of the number of metformin intoxications. Ten times doubled number of inquiries to the Swedish Poison Information Center since 2000. Lakartidningen 2009, 106:994.

7. Bronstein AC, Spyker DA, Cantilena LR Jr, Green JL, Rumack BH, Giffin SL: 2008 Annual Report of the American Association of Poison Control Centers' National Poison Data System (NPDS): $26^{\text {th }}$ Annual Report. Clin Toxicol 47:911-1084.

8. Lalau JD, Race JM: Lactic acidosis in metformin-treated patients. Prognostic value of arterial lactate levels and plasma metformin concentrations. Drug Safety 1999, 20:377-384.

9. Nyirenda MJ, Sandeep T, Grant I, Price G, McKnight JA: Severe acidosis in patients taking metformin - rapid reversal and survival despite high APACHE score. Diabet Med 2006, 23:432-435.

10. Protti A, Russo R, Tagliabue P, Vecchio S, Singer M, Rudiger A, Foti G, Rossi A Mistraletti G, Gattinoni L: Oxygen consumption is depressed in patients with lactic acidosis due to biguanide intoxication. Crit Care 2010, 14:R22.

11. Vitek V, Cowley RA: Blood lactate in the prognosis of various forms of shock. Ann Surg 1971, 173:308-313.

12. Valenza F, Aletti G, Fossali T, Chevallard G, Sacconi F, Irace M, Gattinoni L: Lactate as a marker of energy failure in critically ill patients: hypothesis. Crit Care 2005; 9:588-593.

13. Gatenby RA, Gillies RJ: Why do cancers have high aerobic glycolysis? Nat Rev Cancer 2004, 4:891-899.

14. Brooks GA: Cell-cell and intracellular lactate shuttles. J Physiol 2009, 587:5591-5600.

15. Gores GJ, Nieminen AL, Wray BE, Herman B, Lemasters JJ: Intracellular pH during 'chemical hypoxia' in cultured rat hepatocytes. Protection by intracellular acidosis against the onset of cell death. J Clin Invest 1989, 83:386-396.

doi: $10.1186 /$ cc9404

Cite this article as: Vecchio S, Protti A: Metformin-induced lactic acidosis: no one left behind. Critical Care 2011, 15:107. 